JAN

Leading Global Nursing Research

Original Research: Empirical research - qualitative

\title{
Social acceptance of death and its implication for end- of-life care
}

María Dolores Ruíz-Fernández

Isabel María Fernández-Medina

José Granero-Molina

José Manuel Hernández-Padilla

Matías Correa-Casado

Cayetano Fernández-Sola

First published: 23 March 2021

https://doi.org/10.1111/ian.14836

Funding information:

This research protocol has received funding from the Ministerio de Economía, Industria y Competitividad (Spanish Government) under the funding initiative "Excellence in Scientific and Technical Research" (Protocol number: FFI2016-76927-P - AEI/FEDER, UE). This program is cofunded by the European Union.

How to cite this article: Ruíz-Fernández MD, Fernández-Medina IM, Granero-Molina J, Hernández-Padilla JM, Correa-Casado M, Fernández-Sola C. Social acceptance of death and its implication for end-of- life care. J Adv Nurs. 2021;00:1-10. https://doi.org/10.1111/jan.14836. 


\section{ABSTRACT}

Aims: To understand how the social patterns about death influence end-of-life care from the perspective of healthcare professionals.

Design: A qualitative study according to the theory of Glaser and Strauss.

Methods: A purposeful sample of 47 participants with different roles (nurses, physicians and clinical psychologists) were involved in four focus groups and seventeen interviews in 2017-2019. Responses were audio-recorded, transcribed verbatim and analysed using computer-assisted qualitative data.

Results: A core category 'the theory of social patterns about death' emerged, which is explained by three categories: the culture of concealment and stubbornness towards death, the effort and internal work to make death a part of existence, and the influence of the social patterns of coping with death on end-of life care and healthcare professionals. Our results suggest that social coping with death is affected by a network of concealment and obstinacy towards death.

Conclusion: Recognising death as part of life and thinking about death itself are social coping strategies. Although healthcare professionals occupy a privileged place in this process, the culture of concealment of death influences end-of-life care.

Impact: The social process that leads to the loneliness of the dying in our days has been theorised. However, social acceptance of death also influences healthcare professionals' attitudes towards death. Thus, healthcare professionals' own attitudes may affect the end-of-life care given to dying individuals and their families. The social patterns of death may contribute to the healthcare professionals' negative attitudes towards death. The concept of dignified death has been linked to the notion of humanisation of healthcare. Death should be approached from a more naturalistic perspective by healthcare professionals, healthcare, and academic institutions. 
Key words: grounded theory, healthcare professionals, end-of-life care, dying, nursing, death, attitude to death.

\section{INTRODUCTION}

Human death, a natural and essential part of life (Nelson et al.,2018), is defined as the irreversible cessation of all biological functions (Breibart, 2017). Death is the end of the existence, and it is not possible to define death without referring to consciousness (Breibart, 2017). We could say that a living organism has died when it has irreversibly lost the capacity for consciousness (Maguire, 2019). However, the concept of death is a controversial term which goes beyond the biological and physical death of the individual (Breibart, 2017).

Biological death has been implicitly linked to the concept of social death (Borgstrom, 2017), a term applied to experiences of illness and dying and responses to grief, which refers to the end of our own personal identity and the loss of social connectedness (Králová, 2015; Borgstrom, 2017). This annihilation of our own existence, associated with the disintegration of the body, is the most terrifying experience that human beings inevitably have to face (Pao \& Mahoney, 2018). Even so, physical death has consequences in others as it involves changes in our identity and how we interpret and conceive our lives (Tomasini, 2017). The way in which we socially interpret biological death is closely related to its acceptance (Králová, 2015).

\section{Background}

Death has always been a subject of deep religious, philosophical, and scientific reflections (Kokosalakis, 2020). Nevertheless, in western society it is difficult to accept the idea of death, and some authors suggest that the attitudes to death have regressed (Geijteman, 2018). In the past, death was a public event of a natural and familiar nature (Charlton, 2017). In contrast, these days 
death is represented as a tragic event that generates great suffering both in the dying person and in their family (Hong et al., 2018; Ibañez-Masero et al., 2019). We are currently immersed in a deathdenying society (Cottrell \& Duggleby, 2016), where the dying process is experienced in solitude (Virdun et al., 2015), and bereavement is not socially allowed (Smith, Wild \& Ehlers, 2020). Several factors have contributed to this transformation, examples of which are the security levels of Western societies (Stanley et al., 2011), the decrease in religiosity (Gellie et al.,2015), and the technological advances in medicine, which have separated the biological from other aspects of life (Flannery et al., 2016).

Recent technological advances have made it possible to prolong the life of patients and delay death, which has changed our perception of death (Powazki et al., 2014). Furthermore, the hospital has become as the place where most people die and is socially conceived as the place where people battle against death, changing our consciousness about our own death (Gellie et al., 2015; Lang, 2020). The institutionalisation of death hinders its integration as a natural process, contributing to a lack of reflection on death and taboos around discussions of the dying process (Turnbull, Bosslet \& Kross, 2019; Lang, 2020). Frequently, the lack of home support, the need to do something more for the dying relative, and the fear of seeing them die at home lead relatives to take dying people to the acute care hospital (Granero-Molina et al., 2016). Consequently, healthcare professionals often deal with dying patients in their daily clinical practice (Quinn, 2020).

Healthcare professionals play an indispensable role in caring for dying people and their family (Quinn, 2020). Previous studies have shown that many healthcare professionals have difficulties coping with the death of patients (Prado et al., 2018) and feel uncomfortable and distressed when they think about death (Asadpour et al., 2016; Granero-Molina et al., 2020). The 
attitudes that healthcare professionals have towards death affect the care the dying patient receives (Jiang et al., 2019). The fear of healthcare professionals who have problems coping with their own death or accepting that death is an irremediable consequence of life is reflected in their own attitudes and their avoidance of facing the fact of dying (Ay \& Öz, 2019).

Norbert Elias (1991), a sociologist who theorised death in modern societies, identified two processes when speaking of the repression of death. An individual process, dominated by feelings of guilt and psychological defence mechanisms that drive us to block memories of painful experiences. This means that there are people who are unable to offer help to the dying person because the death of others appears to them as a premonitory sign of their own death. Health professionals are not alien to this process (Ay \& Öz, 2019), which justifies the need to explore the implications of coping with death in the care they provide. The second process identified by Elías is social, where he mentions three possibilities of facing human mortality. First, an ancient and frequent way is to mythologize death through the idea of a later life. Second, avoiding the thought of death by believing in personal immortality or thinking that it is something that does not suit us. Finally, recognising death as a fact of our own existence is the most successful way of coping with death because it saves humans from suffering in the final trance (Elias, 1991). Although Elías theorised the social process that leads to the loneliness of the dying in our days, generally in hospitals (Elias, 1991), it is necessary to explore the point of view of healthcare professionals to complement and substantiate Elías' theory.

\section{THE STUDY}

\section{Aim}

The purpose of this study was to understand how social patterns about death influence endof-life care from the perspective of healthcare professionals. 


\section{Design}

The study followed a qualitative research methodology based on Grounded Theory (GT) as both theoretical approach and a method to collect and analyse data from in-depth interviews and focus groups. This methodology has its origins in symbolic interactionism (SI), which allows us to understand how individuals define a phenomenon through their social interactions (Glaser \& Strauss, 2017; Correa-Casado et al., 2020). For SI behaviour is not determined solely by people's internal, instinctive forces or by environmental forces but rather by a reflective interpretation of social origin and internal and external stimuli (Correa-Casado et al., 2020). Through an inductive analysis of the information, GT aims to generate a theory about a certain phenomenon, social process or behaviour and construct a conceptual schema (Woods, Gapp \& King, 2016). Therefore, GT is a source of knowledge generation through which we can explain how social patterns about death influence end-of-life care from the point of view of healthcare professionals.

\section{Sample/Participants}

Participants were recruited between October 2017 and November 2019 using a purposive sampling procedure and a theoretical sampling strategy. The researchers invited healthcare professionals with experience in end-of-life care from various health centres in southern Spain to participate in the study. Professionals working in hospitals, urban and rural primary care health centres, and palliative care centres were included. The inclusion criteria were: being a healthcare professional, having more than one year of experience in end-of-life care, and agreeing to take part in the study. Healthcare professionals were excluded if they refused to participate in the study or had clinical experience in other areas not related to end-of-life care. Sixty-three healthcare professionals received an email with the study information. Five professional (two nurses and three physicians) declined to take part in the study due to lack of time or other work commitments. $19 \%$ 
of the emails sent did not receive a reply. Interested individuals contacted the interviewer for general information and to arrange an in-person meeting. Forty-six healthcare professionals (4 physicians, 7 clinical psychologists and 35 nurses) with a median age of 31.54 years and a median experience in end-of-life care of 4.44 years took part in the study. Socio-demographic characteristics of the selected participants are shown in Table 1.

TABLE 1. Socio-demographic data of the participants.

\begin{tabular}{|c|c|c|}
\hline & $\begin{array}{c}\text { Focus groups } \\
(n=29)\end{array}$ & $\begin{array}{c}\text { Interviews } \\
\quad(n=17)\end{array}$ \\
\hline \multicolumn{3}{|l|}{ Gender } \\
\hline Woman & $69,0(20)$ & $82,4(14)$ \\
\hline Men & $31,0(9)$ & $17,6(3)$ \\
\hline \multicolumn{3}{|l|}{$\overline{\text { Age }}$} \\
\hline$<30$ & $72,5(21)$ & $58,9(10)$ \\
\hline $31-40$ & $24,1(7)$ & $17,6(3)$ \\
\hline$>41$ & $3,4(1)$ & $23,5(4)$ \\
\hline \multicolumn{3}{|l|}{ Profession } \\
\hline Nurse & $55,5(19)$ & $94,1(16)$ \\
\hline Physician & $20,7(4)$ & 0 \\
\hline Clinical psychologists & $23,8(6)$ & $5,9(1)$ \\
\hline \multicolumn{3}{|l|}{$\begin{array}{l}\text { Professional experience } \\
\text { (years) }\end{array}$} \\
\hline$<10$ & $79,3(23)$ & $76,4(13)$ \\
\hline $11-15$ & $20,7(6)$ & $11,8(2)$ \\
\hline$>15$ & 0 & $11,8(2)$ \\
\hline
\end{tabular}




\section{Data collection}

Initially, from September to December 2017, we conducted four focus group with 29 participants . Later, from February to November 2019, we made 19 in-depth interviews. The focus groups and interviews were carried out in a quiet place on the local university's premises. The focus group was first conducted to facilitate the emergence of important themes from the interaction of the participants, which were extended in the interviews. Although focus groups were characterised by an open approach, we initially used interview guidelines (See Table 2) based on the researchers' previous pre-understanding and the literature review. These guidelines were modified as the preliminary analysis progressed. The focus groups lasted an average of 80 minutes. The quality of application of GT was assured by using the Guideline for Reporting and Evaluating Grounded Theory Research Studies (GURECT) (Berthelsen, Grimshaw-Aagaard, \& Hansen, 2018).

Table 2. Interview protocol.

\begin{tabular}{lll}
\hline $\begin{array}{c}\text { Stage of the } \\
\text { interview }\end{array}$ & \multicolumn{1}{c}{ Subject } & \multicolumn{1}{c}{ Content and example of questions } \\
\hline Introduction & My intention & $\begin{array}{l}\text { I am a member of a research group which studies social } \\
\text { acceptance. Knowing their experiences could help and be } \\
\text { useful for health care professionals and health care } \\
\text { institutions. }\end{array}$ \\
& $\begin{array}{l}\text { Information and } \\
\text { ethical issues }\end{array}$ & $\begin{array}{l}\text { We need to record the conversation in order for the } \\
\text { research team to analyze the data. Only the research team } \\
\text { will have access to the recordings. Participation is totally } \\
\text { voluntary and you can leave the study at any time you }\end{array}$ \\
& $\begin{array}{l}\text { wish. Your identity will be protected, and your name and } \\
\text { personal data will not be revealed. }\end{array}$ \\
& $\begin{array}{l}\text { Verbal acceptance of the participants and signing of the } \\
\text { corresponding document. }\end{array}$
\end{tabular}


Beginning Introductory As a health care professional, what has been your question experience with the death?

Development Conversation Could you tell me what do you think about coping with guide death today?

How do you think death is experienced in hospitals?

Do you think that the health system puts more effort into illness than death?

Do you think that death is perceived equally in all health professions?

Could you tell me if you have ever thought about your moment of dying? Have you stopped to think how your family and loved ones would experience it?

How do you feel in your work dealing with patients who are going to die?

Closing Final question Is there anything else you would like to tell me?

Appreciation Thank you for taking part. Your testimony will be used for the research study. We remain at your disposal if you need anything. You will receive the study upon completion.

Theoretical sampling was achieved in various ways in the different stages of the research process (Conlon et al., 2020) through a variety of data collection techniques (focus group and interviews) and through the selection of additional participants (new interviews). The interviews, which allowed us to explore end-of-life experiences, were conducted by the third and fourth author and lasted from 45 to 60 minutes. The interviews began with sociodemographic data and an introductory question similar to that of the focus group, but new questions arose while conducting the interview, such as 'Has your perception of death changed after being a nurse?', and 'Do you perceive death differently when a child dies?'. The interviews ended with the question 'Is there anything else you would like to contribute on the subject?' Both focus groups and interviews were audio-recorded and transcribed verbatim. After the focus group analysis and some individual interviews, other participants with experience in rural settings, where a more traditional conception 
of coping with death persists, were sought,. Data collection was concluded after reaching theoretical saturation. Theoretical saturation refers to the point at which no significant new knowledge emerges from the data that can better describe, shape, or contextualise the categories that have emerged (Charmaz, 2014; Corbin \& Strauss, 2015). For example, when the "Taboo" code had been assigned to 23 citations, the concept was considered to be sufficiently supported by data.

\section{Ethical considerations}

The study was approved by the Research Ethics Committee of the Department of Nursing, Physiotherapy and Medicine of the University of Almería (12/2017). All participants were informed about the study's aim, participated voluntarily, and signed an informed consent document. The participants' anonymity, privacy and confidentiality were guaranteed. The consolidated criteria for reporting qualitative research checklist, COREQ (Tong et al., 2007) was followed.

\section{Data analysis}

The process of data collection and analysis occurred simultaneously. Data analysis was performed by all authors based on the constant comparison. The content of the interviews and focus groups was analysed line by line, with the help of ATLAS.ti software. We used the open, axial and selective coding technique characteristic of GT (Glaser \& Strauss, 2017). Open coding is the first stage of analysis and allows the data to be encoded transparently in the interviewees' own words, through constant code comparison, grouping into categories, and the construction of new concepts, until data saturation is achieved, that is, until no new information was discovered and the researchers could understand the healthcare professionals' experiences (Glaser \& Strauss, 2017). During data analysis, numerous memos were written to identify and develop conceptual 
ideas and their relationships. Moreover, the memos were used as a guideline for theoretical sampling. Axial coding consisted of identifying relationships between codes, discovering the most significant ones, and grouping them into emerging categories. The final stage in the data analysis process was selective coding, which consisted of integrating the subcategories in order to understand the phenomenon and discover the central concept or category (Table 3). The computerassisted qualitative data analysis ATLAS.ti 8.0 was used to facilitate the comparison and understanding of clusters and meaningful fragments. Throughout the research process, the researchers adopted an open attitude towards understanding the phenomenon. Finally, in order to verify the results the researchers compared their interpretations, and the initial codes and emerging categories were discussed until the researchers reached consensus.

Table 3. Example of the codification process

\begin{tabular}{|c|c|c|c|}
\hline Quote & $\begin{array}{l}\text { Open coding } \\
\text { (Initial open and } \\
\text { in vivo codes) }\end{array}$ & Axial coding & $\begin{array}{l}\text { Category } \\
\text { (Selective } \\
\text { coding) }\end{array}$ \\
\hline $\begin{array}{l}\text { Las personas normalmente no tienen miedo } \\
\text { solo a morirse, tienen miedo a sufrir y más } \\
\text { allá de ello tienen miedo a que los } \\
\text { olviden.'(P-2) } \\
\text { Es la familia mucha veces la que nos } \\
\text { obsesionamos y no queremos limitar la } \\
\text { atención y pedimos más intervenciones. }\end{array}$ & $\begin{array}{l}\text { Fear of death, } \\
\text { Cry hidden } \\
\text { Difficult } \\
\text { Fear to oblivion } \\
\text { Family obstinacy }\end{array}$ & $\begin{array}{l}\text { The rejection of } \\
\text { death }\end{array}$ & \multirow{2}{*}{$\begin{array}{l}\text { Culture of } \\
\text { concealment } \\
\text { and } \\
\text { obstinacy } \\
\text { towards } \\
\text { death }\end{array}$} \\
\hline $\begin{array}{l}\text { La palabra muerte como tal no la suele } \\
\text { utilizar la gente, lo que es una gran } \\
\text { dificultad a la hora de informar a otro } \\
\text { familiar (P1) } \\
\text { Claro le estas ocultando una verdad que se } \\
\text { sabe a voces pero evitamos la palabra } \\
\text { muerte porque nosotros mismos tenemos } \\
\text { miedo a tener que enfrentarnos a esa } \\
\text { situación. (P } 1)\end{array}$ & $\begin{array}{l}\text { Death not } \\
\text { mentioned } \\
\text { Conspiracy of } \\
\text { silence } \\
\text { Hide the prognosis } \\
\text { Hide the diagnosis } \\
\text { Hide death to } \\
\text { children } \\
\text { Taboo }\end{array}$ & $\begin{array}{l}\text { The invisibility of } \\
\text { death }\end{array}$ & \\
\hline
\end{tabular}




\section{Rigour}

The trustworthiness of the study was assured through the criteria of credibility, dependability, transferability, and confirmability (Lincoln \& Guba, 1985). In order to establish credibility, participants who were interviewed had the opportunity to read their responses and confirm the transcripts. In addition, analytic memos contributed to the clarity and justification for emergent codes. Theoretical memos were linked with the codes and the quotations so as to visualise them and check whether the theoretical developments they contain are sufficiently based on data. Dependability was achieved through a detailed description of the selection process, sociodemographic characteristics of the participants, and all steps of the research. The results of the data collection and analysis were compared, and similarities and differences were discussed. In order to support transferability, a detailed description of the methodology and participants' narratives were provided.

\section{FINDINGS}

The results are presented according to the order of the theoretical model developed (see figure 1). The core category is "Social patterns of coping with death" and its influence on end-oflife care. The theoretical model reveals two opposing forms of social coping with death, represented by the categories: (1) The culture of concealment and stubbornness towards death; and (2) The effort and internal work to make death a part of existence. These coping patterns exert a strong influence on healthcare professionals and their conception of end-of-life care, which are discussed in category (3) The influence of the social patterns of coping with death on end-of-life care and healthcare professionals. 


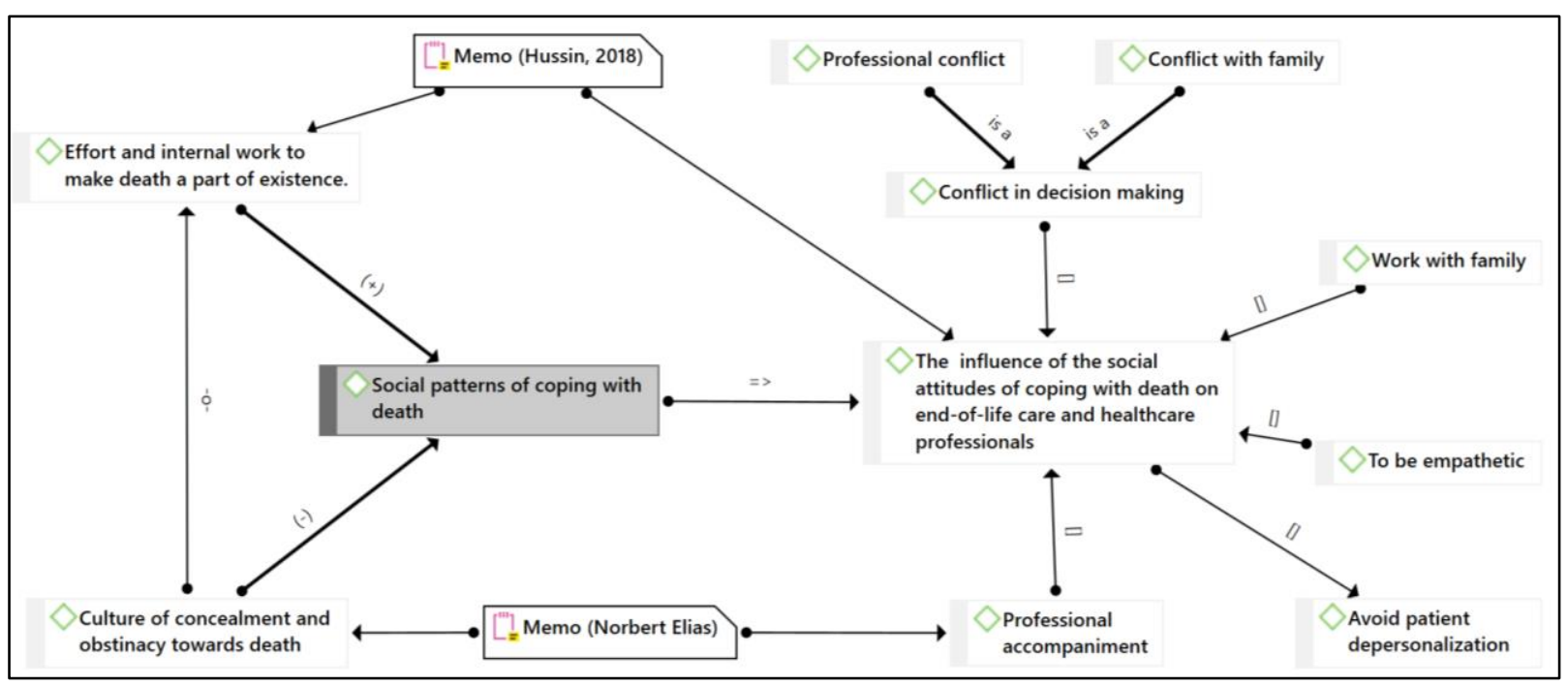

Figure 1. Conceptual map of the patterns coping and its implications on end of life care. Key: [] is part of, -o- is opposed to, (-) negative way, (+) positive way, => is cause of.

\section{Category 1. The culture of concealment and stubbornness towards death.}

The culture of hiding death and obstinacy to maintain life at all costs constitutes a negative way of social coping with death. The participants mentioned that avoiding the thought of death is a form of social coping, and this form of coping has been related to the rejection and invisibility of death.

"Our lives are going to end, we think we are going to be immortal, when death comes it seems to come as a surprise and from the moment you are born you know that you are going to die. We don't take care of our own death" (Participant 16).

Today`s society considers death a taboo subject. We find ourselves immersed in an increasingly technological society that constantly celebrates life without remembering the existence of its end. According to the opinion of our participants, the knowledge and meaning we give to death is influenced by our family environment, society, and the sociocultural group to which we belong. While in some civilisations death is admitted and represented, today's western 
society has built a culture of silence around death. Our participants told us that we avoid talking about death and even naming it because it makes us all uneasy and distressed.

"In our culture whenever death is pronounced it is always seen as something negative, because it scares you, it is something to avoid, you often even try to avoid that word, you try to prevent it from being named" (GF-3)

The participants consider that the practice of religious rites or religious beliefs does not modify the forms of coping. People who are framed in the culture of concealment and rejection can maintain their religious beliefs and disprove the rites, but already in the postmortem phase, without modifying the original attitudes of rejection and silence of acceptance.

“Even though you have faith you don't want to die, nor do you accept it calmly. I have seen patients and families with faith who also hide what they have from their relative" (Participant 9).

The concealment of death has meant that the old mechanisms that socialised death and gave it a place in our daily lives have vanished. Today many families find it difficult to discuss death with children. Healthcare professionals think that death is considered a traumatic event for children, and therefore children are removed from hospitals, funeral rituals, and their questions about death are generally avoided. The hiding of death from children or the wrong explanations about death have caused its experience to become a complicated, painful and far from natural situation.

"Young children are prevented from going to the cemetery, but sometimes that attempt to protect them causes more pain. When we hide death from children because they don't understand it, it causes fear. We are not protecting them, we are protect ing ourselves" (GF-1). 
The denial that we are finite beings whose irremediable destiny is death has led us as a society to look away and distract our thoughts from the end of our own existence. We flee from the suffering caused by dying, which is why, from the point of view of healthcare professionals, death has been transferred from homes to hospitals and mortuaries. Death is no longer a social act, and we experience it alone. In addition, the expression of feelings related to the loss of a loved one is not socially allowed, so we avoid being around people in mourning. The advancement of medical treatments, the increase in life expectancy, and the medicalisation of death have caused the concept of death to move further and further away from us.

"Today, the age especially has risen a lot, older people are taken out of crises, and the disease process take a long time, people die in the hospital surrounded by wires and tubes, and all that makes us less and less aware that one day we have to die" (Participant 8).

\section{Category 2. The effort and internal work to make death a part of existence.}

Being a healthcare professional inevitably puts you in contact with death. Participants talked about the internal work they have to think about death and make death another event in their own existence. Naturalising death, thinking about death, and talking about death are characteristic attitudes of this way of social coping.

"I believe that it is even necessary to live with the word death, not that you are thinking every day I am going to die, but to know that it is going to come and that it is something natural”(GF-2).

The conception of death as an inseparable fact of the life of every living being allows us to live accordingly and value our own existence. Naming it and using the appropriate terminology associated with death without masking it makes us understand that we are beings of earthly transcendence. 
"I believe that first we have to be aware of the word death, and that once we know what it is and we have knowledge of it, we can face it, but if we ignore it, and we leave it a little aside, we never stop thinking about it" (GF-1).

However, it is necessary to reflect on the fact of our own death so that as healthcare professionals we can help others. Participants report that reflection on one's own death is an internal work for all of us and will enable us to talk about the end of life in a natural way. Our own death must be directed and planned in advance just as other life events are planned. As our participants point out, our attitude towards death arises from reflection on our own dying.

"Thinking about it (death) from a young age would be important. So when we approach a patient or family member, if we have internalised how we would like our death to be, we would be more open with the subject" (Participant 11).

Deciding how we want to live our last moments and showing this to others frees our relatives and friends from suffering and the responsibility of deciding the end of life. And therefore, talking about how we want to spend our last moments makes it easier for healthcare professionals to provide quality care according to the needs of patients.

"If you had to die now, would you die in peace? When I speak with patients who have months left, I tell them to talk to their children and to have the peace of mind to say how they want to leave" (GF-4).

The phenomenon of death is little known, and as a consequence, we can only approach it through the experience of others. Our participants affirmed that from the relationships with the act of dying of others we learn that we have to die one day, and from this we generate our construct on death. 
"Death is something that you have to digest on your own and that you learn throughout your life when a family member, a father, a brother, or sister dies..." (Participant 2).

Although acceptance and coping with death are partly mediated by experiences, healthcare professionals admitted that the acceptance and way of coping of our own death and that of others also depends on the conditions in which the death of other beings is experienced. It is thus necessary to differentiate two types of concepts, and coping styles: "death" and "end of life". Death can be conceived as an unexpected sudden act, and the end of life as the consequence of illness or advanced age.

"The death of a family member causes you tremendous grief, but a tragic death in a traffic accident is not experienced the same as that caused by a long illness or old age" (GF-3).

\section{Category 3. The influence of the social patterns of coping with death on end-of life care and healthcare professionals}

Healthcare, especially at the end of life, is not an isolated process that is governed exclusively by clinical standards and guidelines. Precisely in end-of-life care, professionals cannot escape from the social context. The existing coping patterns in the social environment exert a considerable influence on the behaviours, attitudes and decisions that professionals make, through a double mechanism: (1) Faced by the death of their patients, professionals frequently become aware of the fragility of life, human vulnerability, and their own mortality. (2) When the continuity of life and the dignity of the death process are at stake, the beliefs, concerns, fears, and wishes of patients and families exert great pressure on professionals, who sometimes have to put these subjective questions before the evidence or merely clinical issues such as life expectancy or symptom control. The different conceptions of death held by the different actors bring about conflicts in decision-making between professionals, for example between nurses and physicians), 
between relatives, between relatives and patients, and between professionals and patients. Denial and concealment can lead to family or therapeutic stubbornness. Faced with this, professionals identify coping strategies and the humanisation/dignity of the end of life process.

Healthcare professionals stated that camouflaging human mortality has a negative influence on their work environment. Many of our participants, due to the cover-up of family deaths, did not have contact with death until their workplace experiences of death, a fact that left healthcare professionals lacking in coping skills for the death of patients. Those healthcare professionals who had previously experienced family deaths stated that they were better prepared to address this issue more naturally.

"When I got to the hospital, I had never seen a dead person, they had always been hidden from me in my family” (GF-2).

Despite the fact that some healthcare professionals had received information about death and palliative care during their academic training, they considered it insufficient and were not prepared to deal with a dying patient and their family. This preparation was acquired through experience. Relationships with the dying patient and their family made our participants more aware of their own mortality.

"I perfectly remember the first patient who died. What did I have to do at that time? Since then I've accompanied many people during death, and this has changed me" (Participant 11).

Although participants were aware that death is the inevitable result of life, many of them consider it a failure of medicine and therefore do not accept death as such. This perception, prevalent in the medical community, led our participants towards stubbornness and therapeutic ferocity, depriving the patient of a dignified death. However, according to our participants, on 
some occasions the family of the dying patient is an accomplice in this therapeutic ferocity, and doctors are harassed to continue with invasive treatments that will no obtain results. The vast majority of nurses did not share this type of medical perspective, and this was a source of conflict between the different professional categories.

"There are healthcare professionals who have only been taught to heal. Sometimes you see the number of tests on dying patients, and you say, oh my God! But for what? There are patients who cry out to die, but the only thing the family demands is that we save their life" (GF-4).

Another factor that facilitates therapeutic ferocity is the conspiracy of silence. Patients are frequently not informed that the end of their life is near. Healthcare professionals said that, although the majority of patients guess that the end of their life is near, they are not able to communicate it to their family, which is why there is a conspiracy of bilateral silence, which robs patients of the possibility of going through a dignified death according to its principles, and, in addition, false expectations of cure create greater suffering in the patient.

"I had a patient who was not properly informed of what was left of his life and asked you to give him any type of medication. False expectations were created about what was happening, and the patient suffered more from all this" (GF-1).

The processes of coping with death cause a significant emotional drain on healthcare professionals. Those healthcare professionals with little experience of caring for dying patients chose to avoid the care that the dying patient needed as a coping strategy. Another of the strategies adopted by our participants was the emotional disconnection from the process, which means that deaths are treated coldly and as mere statistical data although healthcare professionals with more work experience described the need to help the patient and their family in the process of dying as 
part of their professional work. However, they recognised that the deaths of young patients or children generate a greater emotional impact on them.

There are nurses who are not more involved with the patient or with the family, "'... but there is no more technical help they can give". It is very common for the hospital to hear: today three have died! But those three have names and families (Participant 17).

The participants stated that there are various hospital factors such as lack of privacy and work overload that dehumanise the process of dying. Presence, constant accompaniment, active listening, and emotional support are some of the functions highlighted by the participants to achieve a dignified death. Patient-centered care must be paramount, the family must occupy a privileged place throughout the process, so health activities must be aimed at facilitating the understanding of the situation and favouring their participation in the most active way possible, always respecting the patient's decisions.

"Humanity is undoubtedly linked to the dignity of death, you have to learn to talk to them, to explain what will happen to them by looking into their eyes" (Participant 15).

The participants recognise that breaking the fence of silence imposed on the patient is not easy. But they also maintain that it is necessary to subtly offer the patient the possibility to speak openly about their real concerns. One strategy they suggest is to talk to patients, to give them the opportunity to express themselves. Participants refer to this facilitating process as "creating the moment". This is not to directly address the patient but rather to accompany them and initiate conversations in which the subject of death is subtly hinted at so that it is the patient him or herself who decides whether to continue the conversation or not. 
'Patients want to talk, they want to break that silence, you just mustn't cut them off or force them but give them the opportunity to express themselves, and they will talk about it" (Participant 14).

Emotions remain contained by the feeling of mutual pity (of those nearby towards the patient so as not to embitter their last days and the feelings of the patient towards those nearby, and so as not to increase the suffering of the family members). But given the opportunity to speak, many patients will seize it and be able to let off their emotional overload.

"They might not listen to you, but they may tell you something that you didn't expect, and what they (the patients) really want may come out. And then they thank you very much" (E$1)$.

Another strategy that nurses especially describe is working with the family. The family may be blocked and often do not know themselves how to talk to their dying loved one,

"I... I would like them to work hard... not only with the patient, but with the family so that they assimilate the concept that... I think they don't work on it much. And if they did, so many problems would be avoided ..." (E-1).

\section{DISCUSSION}

Social patterns about death influencing end-of-life care from the perspective of healthcare professionals has been explored in this study. The emerging theory of social patterns about death shows that healthcare professionals are influenced by the culture of concealment and stubbornness towards death. Thus, an effort and internal work are essential to make death a part of existence. Besides, social patterns of coping with death have an effect on end-of-life care and healthcare professionals. Nowadays, social coping with death is influenced by a culture of concealment and 
stubbornness towards death according to our results. Elías (1991) determined that this way of conceiving death is a way of coping in the most developed contemporary societies.

The social denial of death leaves us lacking coping strategies, which are only developed based on our own personal experience (Gagnon \& Duggleby, 2014). Although the first experiences with death partly determine our attitudes towards it (Jiang et al., 2019), healthcare professionals should understand the complicated mental patterns of the acceptance of death of their patient in order to provide quality dying care (Zimmermann, 2012; Kyota \& Kanda, 2019). This statement could be in accordance with the opinion of our participants, who point to an integration of death from an early age. Only if we integrate and accept our own death can we face the death of others. Healthcare professionals with negative perceptions of death tend to experience difficulties in dealing with care for the dying (Hussin et al., 2018). However, healthcare professionals with positive perceptions of death are less afraid of coping with the death of their patients (Hussin et al., 2018). Encouraging healthcare professionals to think about their own death may be a good coping mechanism and may enable them to deliver better dying care (Hong et al., 2018; Hussin et al., 2018). Huertas et al. (2014) identified how, in palliative care professionals, the attitude to face their own death was based on the personal growth that they had experienced with contact with patients and family members. Death experiences have been associated with more positive attitudes towards death (Hong et al., 2018). Even so, healthcare professionals experience difficulties in coping with the death of children or young people (Granek et al., 2016), which could be due to the lack of acceptance that death can happen at any time and stage in the life cycle, not just at an advanced age.

The lack of training in the care of dying patients and negative attitudes towards death cause healthcare professionals to experience situations of fear and stress when they cope with the death 
of their patients (Zheng, Lee and Bloomer, 2018; Puente-Fernández et al., 2020). Therefore, they adopt coping strategies such as escaping from the care that patients need, emotional disconnection, avoiding talking to the family and dying patient, and therapeutic bitterness (Puente-Fernández et al., 2020). This prevents patients from expressing their feelings and last wishes, resulting in a cold and undignified death (Zheng, Lee and Bloomer, 2018).

The integration of death into society requires, according to the results obtained, to work on social coping, from which the need to carry out collective work and self-criticism is extracted to achieve the demystification of death in the sociocultural field (Shin et al., 2016; Hong et al., 2018). For this, it is necessary to return the subject of death to the public sphere, hold debates and educate on the idea of death as the final part of the process that is life (Manjavong et al., 2019).

\section{Limitations}

This study has several limitations. Given the demographic characteristics of the healthcare professionals who participated, the sample might not adequately reflect the experience of healthcare professionals with more clinical experience. The number of participating nurses was significantly higher than that of doctors or psychologists. Although a focus group of physicians was carried out, individual interviews with physicians were not included. Finally, the results of this study are potentially limited by the characteristics of today's western society as in less industrialised societies, or in those with lower levels of security than western ones (Elías, 1991), social patterns of coping with death may differ greatly from those of western societies.

The grounded theory that emerges here needs to be confirmed with other populations of healthcare professionals, patients and families. Similar studies could be conducted in other societies and cultures in order to compare different forms of the social coping with death. 


\section{CONCLUSION}

The theory generated explains how the social concealment and stubbornness towards death has influenced the perception of healthcare professionals and the management of dying patients. The social context exerts great influence on the attitudes and decisions that health professionals adopt in end-of-life care. Professionals have to manage numerous conflicts in decision-making, which may be conflicts between professionals, or between professionals, families and patients. The professionals described various strategies to overcome the effects of the social context in end-oflife care: being empathic with family members, the patient, and other professionals; accompaniment, giving an opportunity for open communication as far as the patient wishes; avoiding depersonalisation of the dying person; and working with the family to facilitate honest communication with their loved one and avoiding conflict in decision-making.

\section{Conflict of Interest statement}

The authors declare that there is no potential conflicts of interest.

\section{Funding}

This research protocol has received funding from the Ministerio de Economía, Industria y Competitividad (Spanish Government) under the funding initiative "Excellence in Scientific and Technical Research" (Protocol number: FFI2016-76927-P - AEI/FEDER, UE). This program is co-funded by the European Union.

\section{References}

Asadpour, M., Sabzevari, L., Ekramifar, A., \& Bidaki, R. (2016). The attitude of medical students toward death: A cross-sectional study in Rafsanjan. Indian journal of palliative care, 22 (3), 354361. https://doi.org/10.4103/0973-1075.185084. 
Ay, M.A., \& Öz, F. (2019). Nurses attitudes towards death, dying patients and euthanasia: A descriptive study. Nursing Ethics, 26 (5), 1442-1457. https://doi.org/10.1177/0969733017748481. Berthelsen, C.B., Grimshaw-Aagaard, S., \& Hansen, C. (2018). Developing a guideline for reporting and evaluating grounded theory research studies (GUREGT). International Journal of Health Sciences, 6 (1), 64-76. https://doi.org/10.15640/ijhs.v6n1a8

Borgstrom E. (2017). Social death. QJM: monthly journal of the Association of Physicians, 110 (1), 5-7. https://doi.org/10.1093/qjmed/hcw183

Breibart W. (2017). On the inevitability of death. Palliative \& supportive care, 15 (3), 276-278. https://doi.org/10.1017/S14789517000372

Charlton R. (2017). Talking to patients and relatives about dying. British journal of hospital medicine (London, $\quad$ England: $\quad 2005), \quad 78 \quad$ C61-C63. https://doi.org/10.12968/hmed.2017.78.4.C61.

CHARMAZ, K. (2014) Constructing grounded theory. London: Sage.

Conlon, C., Timonen, V., Elliott-O'Dare, C., O'Keeffe, S., \& Foley, G. (2020). Confused about theoretical sampling? engaging theoretical sampling in diverse grounded theory studies. Qualitative health research, 30(6), 947-959. https://doi.org/10.1177\%2F1049732319899139.

Corbin, J., Strauss, A. (2015). Basics of qualitative research: Techniques and procedures for developing grounded theory (4th ed.). Thousand Oaks, CA: Sage.

Correa-Casado, M., Hernández-Padilla, J.M. (2020). Interaccionismo simbólico y teoría fundamentada. In: Fernández-Sola, C., Granero-Molina, J., Hernández-Padilla, J.M. Comprender para cuidar. Avances en Investigación cualitativa en Ciencias de la Salud; Almería: EDUAL. [Google Bocks].

Cottrell, L., \& Duggleby, W. (2016). The "good death": An integrative literature review. Palliative 
\& supportive care, 14 (6), 686-712. https://doi.org/10.1017/S1478951515001285.

Elias N. (1991). Ober die Einsamkeit der Sterbenden. Frankfurt am Main: Suhrkamp.

Flannery, L., Ramjan, L.M., \& Peters, K. (2016). End-of-life decisions in the intensive care unit (ICU) - Exploring the experiences of ICU nurses and doctors - A critical literature review. Australian critical care: official journal of the Confederation of Australian Critical Care Nurses, 29 (2), 97-103. https://doi.org/10.1016/j.aucc.2015.07.004.

Gagnon, J., \& Duggleby, W. (2014). The provision of end-of-life care by medical-surgical nurses working in acute care: a literatur review. Palliative \& supportive care, 12 (5), 393-408. https://doi.org/10.1017/S1478951513000965.

Geijteman E. (2018). Denying the inevitability of death. European journal of heart failure, 20 (5), 835-836. https://doi.org/10.1002/ejhf.1110.

Gellie, A., Mills, A., Levison, M., Stephenson, G., \& Flynn, E. (2015). Death: a foe to be conquered?Questioning the paradigm. Age and Ageing, 44 (1), 7-10. https://doi.org/10.1093/ageing/afu116

Glaser, B., \& Strauss, A. (2017). Discovery of grounded theory: Strategies for qualitative research. New York: Routledge.

Granek, L., Barrera, M., Scheinemann, K., Bartels, U. (2016). Pediatric oncologists' coping strategies for dealing with patient death. Journal of psychosocial oncology, 34 (1-2), 39-59. https://doi.org/10.1080/07347332.2015.1127306

Granero-Molina, J., Díaz-Cortés, M., Hernández-Padilla, J.M., García-Caro, M.P., \& FernándezSola, C. (2016). Loss of dignity in end-of-life care in the emergency department: A phenomenological study with health professionals. Journal of emergency nursing, 42 (3), 233239. https://doi.org/10.1016/j.jen.2015.10.020. 
Granero-Molina, J., Fernández-Férez, A., Fernández-Sola, C., Ruiz-Fernández, M.D., JiménezLópez, F.R., López-Rodríguez, M.M., Fernández-Medina, I.M., \& Hernández-Padilla, J.M. (2020). Society facing death and its implications for end-of-life care: a qualitative study with healthcare professionals (Research Project FFI2016-76927-P- AEI/FEDER, UE). Palliative Medicine, 34(1_suppl), 156-157. https://doi.org/10.1177/0269216320958098

Hong, M., Hong, S., Adamek, M.E., \& Kim, M.H. (2018). Death attitudes among middle-aged Koreans: Role of end-of-life care planning and death experiences. International journal of aging \& human development, 86 (1), 51-68. https://doi.org/10.1177/0091415016689473.

Huertas, L.A., Allendez Pérez, S.R., Verastegui Avilés, E. (2014). Creencias, actitudes y ansiedad ante la muerte en un equipo multidisciplinario de cuidados paliativos oncológicos. Psicooncología, 11(1), 101. https://doi.org/10.5209/rev_PSIC.2014.v11.n1.44920

Hussin, E., Wong, L.P., Chong, M.C., \& Subramanian, P. (2018). Factors associated with nurses’ perceptions about quality of end-of-life care. International nursing review, 65 (2), 200-208. https://doi.org/10.1111/inr.12428

Ibañez-Masero, O., Carmona-Rega, I.M., Ruiz-Fernández, M.D., Ortiz-Amo, R., Cabrera-Troya, J., Ortega-Galán, Á.M. (2019). Communicating health information at the end of life: The caregivers' perspectives. International journal of environmental research and public health, 16 (14), 2469. https://doi.org/10.3390/ijerph16142469.

Jiang, Q., Lu, Y., Ying, Y., \& Zhao, H. (2019). Attitudes and knowledge of undergraduate nursing students about palliative care: An analysis of influencing factors. Nurse education today. 2019, 80, 15-21. https://doi.org/10.1016/j.nedt.2019.05.040.

Kokosalakis N. (2020). Reflections on death in philosophical/existential context. Society, 1-8. https://doi.org/10.1007/s12115-020-00503-5. 
Králová J. (2015). What is social death?. Contemporary Social Science: Journal of the Academy of Social Sciences, 10 (3), 235-248. https://doi.org/10.1080/21582041.2015.1114407

Kyota, A., \& Kanda, K. (2019). How to come to terms with facing death: a qualitative study examining the experiences of patients with terminal cancer. BMC palliative care, 18 (1), 33. https://doi.org/10.1186/s12904-019-0417-6

Lang A. (2020). The good death and the institutionalization of dying: An interpretive analysis of the Austrian discourse. Social science \& medicine (1982), 245, 112671. https://doi.org/10.1016/j.socscimed.2019.112671.

Lincoln, Y.S., \& Guba, E. (1985). Naturalistic Inquiry (SAGE Publi). Newbury Park, CA.

Maguire A. (2019). Towards a holistic definition of death: the biological, philosophical and social deficiencies of brain stem death criteria. The New bioethics, 25 (2), 172-184. https://doi.org/10.1080/20502877.2019.1606138

Manjavong, M., Srinonprasert, V., Limpawattana, T., Chindaprasirt, J., Pairojkul, S., Kuichanuan, T., Kaiyakit, S., Juntararuangtong, T., Yongrattanakit, K., Pimporm, J., \& Thongkoo, J. (2019). Comparison of Thai older patients' wishes and nurses' perceptions regarding end-of-life care. Nursing ethics, 26 (7-8), 2006-2015. https://doi.org/10.1177/0969733019826410

Nelson, K.E., Wright, R., Abshire, M., \& Davidson, P.M. (2018). All things death and dying: Health professional students participating in the death café model. Journal of palliative medicine, 21 (6), 850-852. https://doi.org/10.1089/jpm.2017.0440

Pao, M., \& Mahoney, M.R. (2018). "Will you remember me?”: Talking with adolescents about death and dying. Child and adolescent psychiatric clinics of North America, 27 (4), 511-526. https://doi.org/10.1016/j.chc.2018.05.001 
Powazki, R., Walsh, D., Cothren, B., Rybicki, L., Thomas, S., Morgan, G., Karius, D., Davis, M.P. \& Shrotriya, S. (2014). The care of the actively dying in an academic medical center: a survey of registered nurses' professional capability and comfort. The American journal of hospice \& palliative care, 31 (6), 619-27. https://doi.org/10.1177/1049909113505194.

Prado, R.T., Leite, J.L., Castro, E., Silva, L., \& Silva, Í.R. (2018). Uncovering care for patients in the death/dying process and their families. Desvelando os cuidados aos pacientes em proceso de norte/morrer e às suas famílias. Revista gaucha de enfermagem, 39, e20170111. https://doi.org/10.1590/1983-1447.2018.2017-0111.

Puente-Fernández, D., Lozano-Romero, M.M., Montoya-Juárez, R., Martí-García, C., CamposCalderón, C., \& Hueso-Montoro, C. (2020). Nursing professionals' attitudes, strategies, and care practices towards death: A systematic review of qualitative studies. Journal of nursing scholarship: an official publication of Sigma Theta Tau International Honor Society of Nursing, 52 (3), 301-310. https://doi.org/10.1111/jnu.12550

Quinn B. (2020). Living with uncertainty and the reality of death. International journal of palliative nursing, 26 (6), 278-283. https://doi.org/10.12968/ijpn.2020.26.6.278.

Shin, D.W., Lee, J.E., Cho, B., Yoo, S.H., Kim, S., \& Yoo, J.H. (2016). End-of-life communication in Korean older adults: With focus on advance care planning and advance directives. Geriatrics \& gerontology international, $16 \quad$ (4), 407-415. https://doi.org/10.1111/ggi.12603

Smith, K.V., Wild, J., \& Ehlers, A. (2020). The masking of mourning: Social disconnection after bereavement and its role in psychological distress. Clinical psychological science: a journal of the Association for Psychological $\quad$ Science, $\quad 8 \quad$ 464-476. https://doi.org/10.1177/2167702620902748. 
Stanley, L \& Wise, S. (2011). The domestication of death: The sequestration thesis and domestic figuration. Sociology, 45 (6), 947-962. https://doi.org/10.1177/0038038511416153.

Sullivan, S.S., \& Dickerson, S.S. (2016). Facing death: A critical analysis of advance care planning in the United States. ANS. Advances in nursing science, 39 (4), 320-332. https://doi.org/10.1097/ANS.0000000000000138

Tomasini F. (2017). Remembering and disremembering the dead: Posthumous punishment, harm and redemption over time. London (UK): Palgrave Macmillan.

Tong, A., Sainsbury, P., \& Craig, J. (2007). Consolidated criteria for reporting qualitative research (COREQ): a 32-item checklist for interviews and focus groups. International journal for quality in health care: journal of the International Society for Quality in Health Care, 19 (6), 349-357. https://doi.org/10.1093/intqhe/mzm042

Turnbull, A.E., Bosslet, G.T., \& Kross, E.K. (2019). Aligning use of intensive care with patient values in the USA: past, present and future. The Lancet. Respiratory medicine, 7 (7), 626-638. https://doi.org/10.1016/S2213-2600(19)30087-6.

Turner, V., \& Flemming, K. (2019). Socieconomic factors affecting access to preferred place of death: A qualitative evidence synthesis. Palliative medicine, 33 (6), 607-617. https://doi.org/10.1177/0269216319835146.

Virdun, C., Luckett, T., Davidson, P.M., \& Phillips, J. (2015). Dying in the hospital setting: A systematic review of quantitative studies identifying the elements of end-of-life care that patients and their families rank as being most important. Palliative medicine, 29 (9), 774-96. https://doi.org/10.1177/0269216315583032.

Woods, P., Gapp, R, \& King, M.A. (2016). Generating or developing grounded theory: methods to understand health and illness. International journal of clinical pharmacy, 38 (3), 663-70. 
https://doi.org/10.1007/s11096-016-0260-2.

Zheng, R., Lee, S.F., \& Bloomer, M.J. (2018). How nurses cope with patient death: A systematic review and qualitative meta-synthesis. Journal of clinical nursing, 27 (1-2), e39-e49. https://doi.org/10.1111/jocn.13975

Zimmermann, C. (2012). Acceptance of dying: A discourse analysis of palliative care literature. Social Science \& Medicine, 75 (1), 217-224. https://doi.org/10.1016/j.socscimed.2012.02.047 